\begin{tabular}{|c|c|c|}
\hline$A r$ & $\begin{array}{l}\text { European Association for the } \\
\text { Development of Renewable Energies,Environment } \\
\text { and Power Quality (EA4EPQ) }\end{array}$ & $\begin{array}{l}\text { International Conference on Renewable Energies and Power Quality } \\
\text { (ICREPQ'12) } \\
\text { Santiago de Compostela (Spain), 28th to 30th March, } 2012\end{array}$ \\
\hline
\end{tabular}

\title{
Voltage margin control for offshore multi-use platform integration
}

\author{
V.Mier ${ }^{1}$, P.G.Casielles ${ }^{1}$, J.Coto ${ }^{1}$ and L.Zeni ${ }^{2}$ \\ ${ }^{1}$ Department of Electrical Engineering \\ E.P.I, University of Oviedo \\ Phone/fax number: +34 985 182415, e-mail: mierveronica@uniovi.es, pcasiell@uniovi.es, jcoto@uniovi.es \\ ${ }^{2}$ Vestas Wind Systems and Technical University of Denmark \\ Phone: +4541820912, e-mail: lozen@vestas.com
}

\begin{abstract}
This paper discusses a multiterminal direct current (MTDC) connection proposed for integration of offshore multi-use platforms into continental grids. Voltage source converters (VSC) were selected for their suitability for multiterminal dc systems and for their flexibility in control. A five terminal VSC-MTDC which includes offshore generation, storage, loads and ac connection, was modeled and simulated in DigSILENT Power Factory software. Voltage margin method has been used for reliable operation of the MTDC system without the need of fast communication. Simulation results show that the proposed system was able to maintain constant $\mathrm{dc}$ voltage operation during fluctuations in the generation and changes in the demand. Moreover, it was able to secure power supply to passive loads during loss of a dc voltage regulating terminal and to perform a dispatch scheme where it is possible to buy, sell or store energy attending to the price in the electricity market.
\end{abstract}

\section{Key words}

Multi-use offshore platform, multiterminal VSC, ocean offshore energies, voltage margin control, Digsilent Power Factory.

\section{Introduction}

Intensive research efforts are underway in Europe to reduce the greenhouse gas emissions, to increase the share of consumption supplied by renewable energy and to decrease the primary energy use. The energy package plan, "20-20-20" targets, was approved by the EU members in March 2007 with the aim of improving the energy security and strengthen its competitiveness.

The European Commission Research and Investigation is currently supporting research projects on different topics, where multi-use platforms constitute an important key within the FP7 Ocean 2011programme: "The Ocean of tomorrow" [1]. The platforms shall target ocean renewable energy and in particular offshore power, aquaculture and the related transport maritime services. On the other hand, the University of Oviedo was awarded in 2009 with the status of Campus of International Excellence that implied the creation of the Cluster of Energy, Environment and Climate Change. The main project this Cluster is developing is called "SeaAsturlab" [2]. This facility specializes in the development of R\&D\&i projects related to the generation, transportation and storage of offshore energies. In this context, the VSCMTDC transmission and the multiterminal configuration play an important role.

Regarding HVDC systems there are two possible technologies to consider: Line Commutated Converters and Voltage Source Converters. However, VSC-HVDC features full controllability of the dc network and makes it easier to connect multiple converters to the same DC grid compared to classic Line Commutated Converter (LCC) HVDC. Furthermore, VSC-HVDC can be used to feed passive networks and can be kept compact, which makes it more suitable to build connections to offshore platforms.

The integration of offshore deep sea wind farms is the best example where multiterminal configuration has been proposed [3], although it is also possible to find MTDC's in applications such as: underground urban subtransmission and distribution systems [4], shipboard power supplies [5],....Regarding the way of controlling this kind of installation, two main different methods can be found in the literature [6], [7]. The first is the droop control which principles are similar to its application in the frequency control of the ac systems [8], and the second is called the voltage margin control method, based on the maintenance of the dc voltage by one terminal (slack). But, in the case of a multi-use offshore platform, it is necessary to investigate deeper in the principles of control and coordination due to the complexity of the system: different generation technologies combined with storage elements and loads will be present. The voltage margin control method is proposed in this paper to achieve this objective.

This paper presents a five terminal VSC-HVDC model linking an onshore grid and an offshore multi-use platform which includes wind generators, tidal and wave 
power, storage systems and demand, and discusses the control strategy and the coordination between terminals.

\section{VSC Modelling and Control}

A simplified single line diagram of the VSC, neglecting the semiconductor losses, is shown in Fig.1, where the point $\mathrm{X}$ is highlighted due to its importance as it is the common coupling point (PCC).

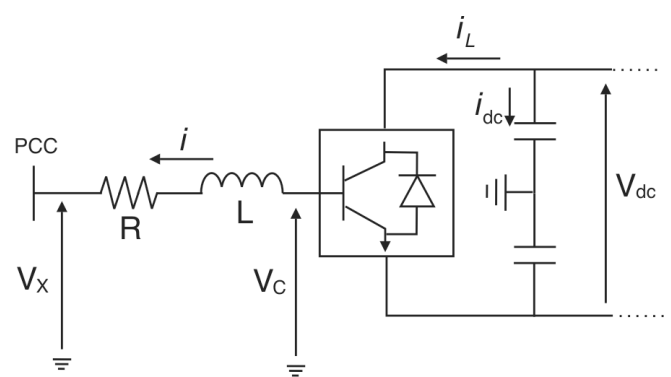

Fig.1. Single line diagram of VSC converter.

Using the $a b c$ reference frame and considering positive the current that goes out the converter, it is possible to find the following relationship for the voltage across the ac reactor:

$$
V_{c_{a b c}}-V_{x_{a b c}}=L \frac{d i_{a b c}}{d t}+R i_{a b c}
$$

Where $\mathrm{V}_{\text {cabc }}, \mathrm{V}_{\mathrm{xabc}}$ and $\mathrm{i}_{\mathrm{abc}}$ are the three phase voltage for the converter output, the voltage in the PCC and the current through the reactor respectively. A transformation of the reference frame from $a b c$ to $d q$ coordinates is made in order to be helpful for the control design. Thus, as detailed in [2], equation (1) becomes:

$$
V_{c_{d q}}-V_{x_{d q}}=L \frac{d i_{d q}}{d t}+R i_{d q}+j \omega L i_{d q}
$$

The measure of the real time phase angle, necessary for the coordinate transformation, is made by a phase locked loop (PLL). Moreover, the $d$ axis from de $d q$ reference frame is considered aligned with the voltage phasor of phase $a$ at PCC in stationary $a b c$ reference frame. This assumption leads to $V_{X d}=V_{x}$ and $V_{X q}=0$. Therefore, equation (2) can be expanded as:

$$
\frac{d}{d t}\left[\begin{array}{l}
i_{d} \\
i_{q}
\end{array}\right]=\left[\begin{array}{cc}
\frac{-R}{L} & \omega \\
-\omega & \frac{-R}{L}
\end{array}\right]\left[\begin{array}{l}
i_{d} \\
i_{q}
\end{array}\right]+\frac{1}{L}\left[\begin{array}{ll}
V_{c d} & -V_{x d} \\
V_{c q} & -V_{x q}
\end{array}\right]
$$

Pulse width modulation (PWM) control technique allows changes in the amplitude of the ac output voltage by changing the modulation index of the converter, as follows:

$$
V_{c}=\frac{M}{2} V_{d c}
$$

Where $M$ is the modulation index which value is between 0 and 1 if normal region is desired.

Substituting equation (4) in equation in (3) we get:

$$
\frac{\mathrm{d}}{\mathrm{dt}}\left[\begin{array}{l}
i_{d} \\
i_{q}
\end{array}\right]=\left[\begin{array}{cc}
\frac{-R}{L} & \omega \\
-\omega & \frac{-R}{L}
\end{array}\right]\left[\begin{array}{l}
i_{d} \\
i_{q}
\end{array}\right]-\frac{1}{L}\left[\begin{array}{l}
V_{x d} \\
V_{x q}
\end{array}\right]+\frac{V_{d c}}{2 L}\left[\begin{array}{l}
M_{d} \\
M_{q}
\end{array}\right]
$$

The detailed description of VSC control is out of the scope of the present work but helpful descriptions about the inner and the outer controllers of the VSC can be found in [9] [10].

\section{Proposed Multiterminal HVDC System}

A multiterminal VSC-HVDC (MTDC) consists of three or more VSC terminals with different control objectives. In this paper a five terminal VSC system is proposed and analyzed.

The onshore grid is linked to the offshore generation technologies- wind energy, wave and tidal power-, to the storage elements and to the platform load describing a parallel multiterminal HVDC topology. An extensive comparison between different MTDC topologies can be found in [11]. The schematic diagram of the proposed MTDC is shown in Fig. 2.

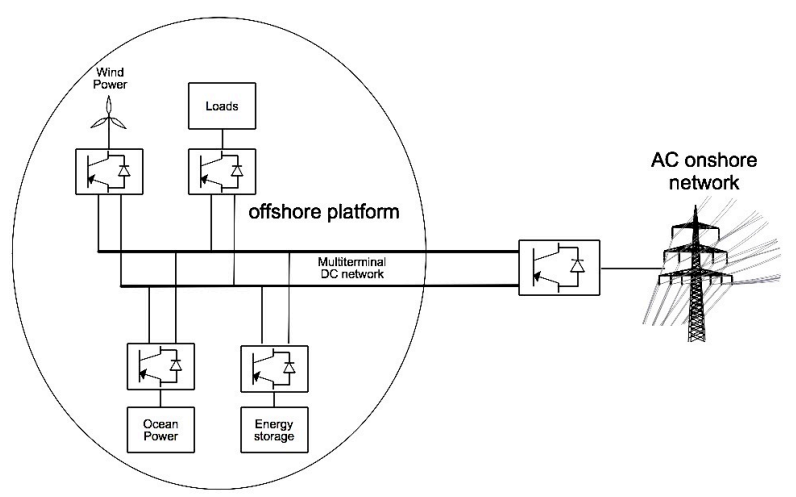

Fig. 2. Proposed multiterminal interconnection

\section{A. Wind farm generation}

Turbines and farms can be modelled with different level of detail, depending on the studies they are to be used for. Detailed investigations concerning wind farm connection and its stable interaction with the grid must sometimes make use of very detailed models that allow for an accurate evaluation of the dynamic behaviour of the turbines.

As this study is more generally concerning the HVDC grid and how its control handles the power disturbances, a very simplified wind farm model can be applied in order to achieve a first assessment of the issues. Only the power injection from the wind farm is deemed to be important, leaving the analysis of other issues to more specific studies.

As such, the wind farm is modeled as a controllable power source that injects power into the DC grid through a converter, depending on the available aerodynamic power from the wind. A scaled-up power-curve-based model has been chosen. One wind speed is considered for the whole wind farm, thus lumping all the wind turbines 
together in one point, i.e. scaling up and aggregating their power curve. Figure 3 depicts the block diagram of the wind farm model.

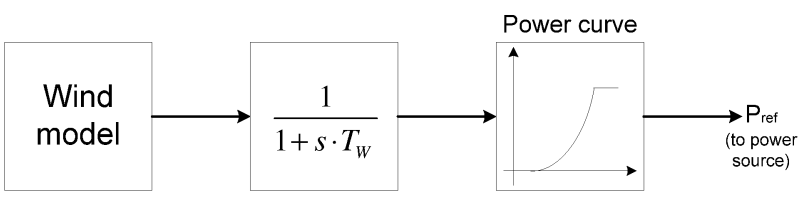

Fig. 3.Simplified wind farm model.

The realistic wind speed time series has been generated by CorWind, developed at DTU Wind Energy and is filtered by a first order block, which time constant approximates the behaviour of the wind farm, including averaging of the wind over the swept area, control and inertia of the turbine, etc. The filtered wind speed is then input to a power curve block, which reproduces a power curve of a $2 \mathrm{MW}$ variable speed wind turbine, scaling it up to the rated power of the whole wind farm. The power curve thus feeds the wind power production into the HVDC node the wind farm is connected to, thus assuming that the component instantaneously injects all the power coming from the wind.

It is worth remarking that such a simplified wind farm model can be utilized only for studying how the HVDC grid handles the power fluctuations coming from a node depending on the adopted control strategy. Any more detailed study should rely upon a more solid wind farm representation, dropping some of the many approximations introduced here.

\section{B. Ocean energy generation}

It includes the energy production from tidal current and wave energy. A brief description with the main references from the technical literature is given for both kinds of energies.

Although there is a high potential for the extraction of electricity from the waves, the technology is still in its beginning. The so-called WEC's (Wave Energy Converters) are responsible for the conversion of the energy from the waves into electrical energy. In order to achieve this aim, a great number of WECs are under development [12]: OWC, overtopping, point absorbers, Archimedes wave swing, pelamis... Apart from the converter itself, it is needed to pay special attention to the control system that will assure the maximum power extraction in every operating condition. There exists a list of control techniques which are mainly considered [13], e.g. reactive control, phase and amplitude, switching control, latching control... Furthermore, aspects such as the influence and the requirements for the connection between wave farms and the common grid should also be taken into consideration.

Another type of ocean energy is the energy that comes from the tides; it is known as tidal energy or marine current. As in the case of the wave energy the potential is huge, oceans cover more than $70 \%$ of Earth's surface. But this renewable energy adds another benefit that is its predictable and regular character. The tides are related to the gravitational effects of the motion of the earth, the sun and the moon. Through kinetic energy converters it is possible to harness it [14]. Cost effectiveness is still under development.

\section{Storage system}

The fact of including a storage element in the multiterminal network improves the capabilities of the platform due to the new possibilities it implies.

The operation strategy will be based on two different facts: the level of generation from the wind and the ocean energies, and the spot price in the electricity market which it is connected to.

Considering this two factors, the storage system could perform any dispatch scheme: storage power from the offshore generators, import from the ac grid, export to the ac grid, islanding operation....as long as the continuous supply to the load was guaranteed.

The simplified model used in this multiterminal network for the storage presents, during the whole simulation time, a sufficient state of charge (SOC) for carrying out the programmed events. The converter used for the connection with the multiterminal grid will be responsible for the maintenance of the dc voltage level following the principle of the voltage margin method explained in the next section whenever it works within its power limits $( \pm 20 \mathrm{MW})$.

\section{Load}

In the proposed offshore multi-use platform, there will be different loads, such as labs, communication systems, aquaculture facilities... whose supply need to be secured and uninterrupted all the time.

The load is represented here as a 3 phase demand whose peak value is $10 \mathrm{MW}$. The VSC control needed for this application is $V_{a c}$ type, controlling the $a c$ voltage in the connection point. [6],[15],[16].

\section{E. Onshore AC grid}

The multi-use offshore platform is connected to a132 $\mathrm{kV}$ AC grid through a submarine direct current cable $( \pm$ $50 \mathrm{kV}$ ). The VSC converter used for its connection to the multi-use platform will perform a control methodology in order to:

- Work bidirectionally: importing or exporting power.

- Control the power flow with the platform, buying or selling a fixed amount of active power.

- Maintain the dc voltage level through a voltage margin control, cooperating with the storage system. 


\section{Control methodology}

The voltage margin control method (VMM) was first developed by [17]. Whenever a multiterminal system is considered, the maintenance of a constant dc voltage level is one of the most important issues. The VMM assigns this task to one of the terminals that will act as a slack bus while the other will develop a constant power control. The variations in power flow and the losses will be assumed by this slack bus. In Fig.4 it appears the P-Vdc characteristic implemented in a converter.

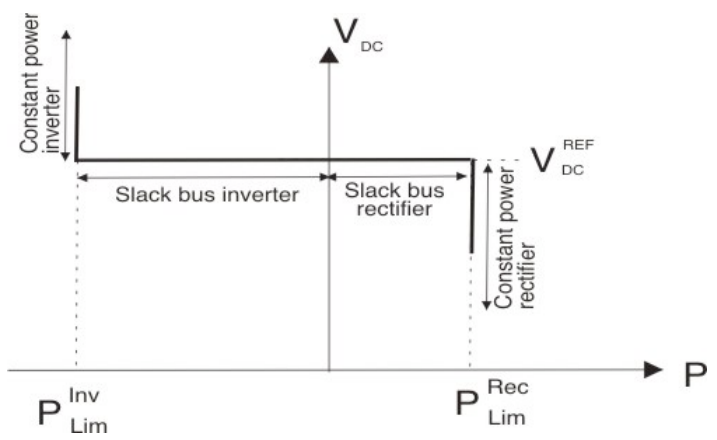

Fig. 4.Vdc-P characteristic curve of a VSC converter

As it can be seen in Fig. 5, converter $A$ will steer the dc voltage to track its reference while it is working within its limits of active power. Once these limits are reached, converter $A$ will no longer be able to control the dc voltage and it will act as constant power terminal.

Under this circumstance, converter $B$ has to be responsible of the dc voltage to follow a new reference value and secure its stability. The difference between the voltage references of the two terminals is called "voltage margin" and it represents the essence of the method.

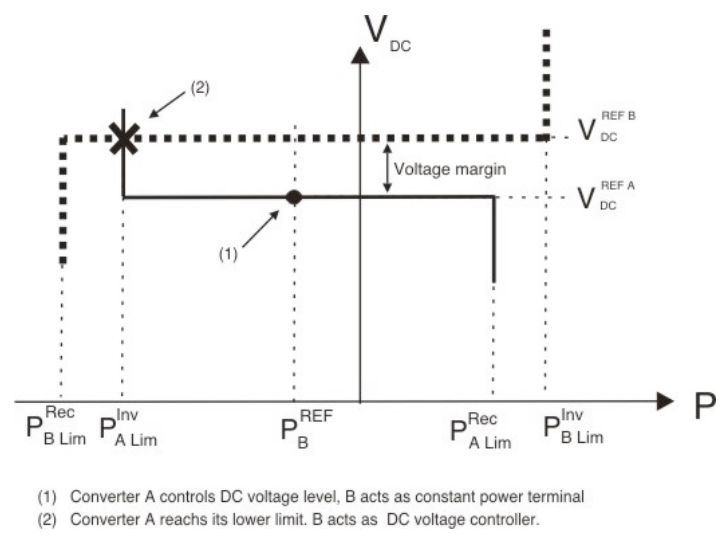

Fig. 5.VMM applied to two terminal operation.

The continuous measuring of the dc voltage level makes possible the coordination between two terminals without real-time communication between them. This characteristic is especially helpful for the offshore multiuse platforms due to the large number of elements interconnected.
Finally, in Fig. 6 it is represented the needed control scheme for the implementation of the voltage margin in a VSC converter.

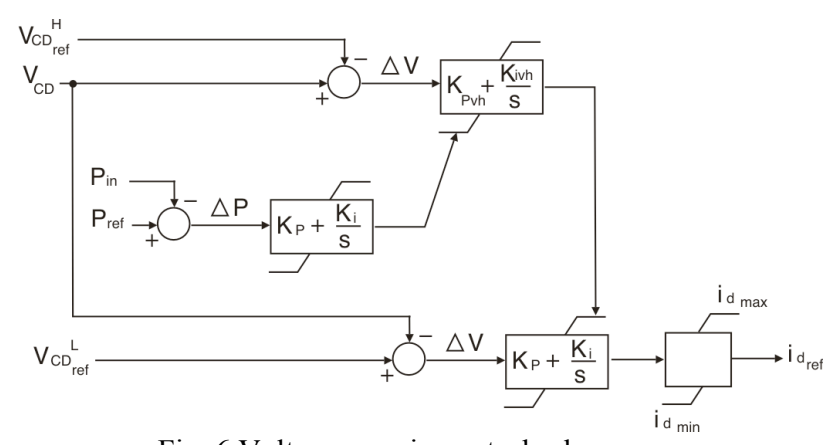

Fig. 6.Voltage margin control scheme.

\section{Simulation and Results}

Simulation studies of the proposed MTDC network have been performed using DigSILENT PowerFactory. The main data about the converter ratings and voltage are given in Table I.

TableI.-Converter rating and operating voltage for the system.

\begin{tabular}{|c|c|c|}
\hline & $\begin{array}{c}\text { Converter rating } \\
\text { (MVA) }\end{array}$ & Uref (pu) \\
\hline Offshore generation & 20 & 1.0 \\
\hline Load & 10 & 1.0 \\
\hline Storage system & 25 & 1.0 \\
\hline Onshore ac grid & 50 & $0.97-1.03$ \\
\hline
\end{tabular}

For all the study cases, the generation pattern is shown in Fig. 7(a), where a series of wind and ocean energy is simulated. In order to be able to consider the electricity price as a factor of influence, it is supposed that there is a first period $\left(t<t_{3}\right)$ where the electricity market price is high whereas the rest of the time it is low. Considering these two variables: offshore production and cost; a list of events is programmed in order to validate the voltage margin capability for this application (Table II)

The initial conditions for the system to start up are: 5 MW demand and a scheduled power interchange with the ac grid importing $15 \mathrm{MW}$.

TableII. - Order of events in the MTDC network.

\begin{tabular}{|c|l|}
\hline Time & \multicolumn{1}{c|}{ Event description } \\
\hline $\boldsymbol{t}_{\boldsymbol{o}}$ & Start up (with the described initial conditions) \\
\hline $\boldsymbol{t}_{\boldsymbol{1}}$ & Demand increase till 8 MW \\
\hline $\boldsymbol{t}_{\boldsymbol{2}}$ & Decrease in the demand till 5 MW \\
\hline $\boldsymbol{t}_{\boldsymbol{3}}$ & Injection of 10 MW from the ac grid \\
\hline $\boldsymbol{t}_{\boldsymbol{4}}$ & Connection loss with the onshore grid \\
\hline $\boldsymbol{t}_{\boldsymbol{5}}$ & Connection restored \\
\hline $\boldsymbol{t}_{\boldsymbol{6}}$ & 3MW demand increase \\
\hline $\boldsymbol{t}_{\boldsymbol{7}}$ & Demand decrease till 5 MW \\
\hline
\end{tabular}

The results of the power sharing between the terminals, the dc voltage and the ac voltage in each converter are shown in Fig.7 (b) (c) (d), where specific time periods appear highlighted in order to be explained: 

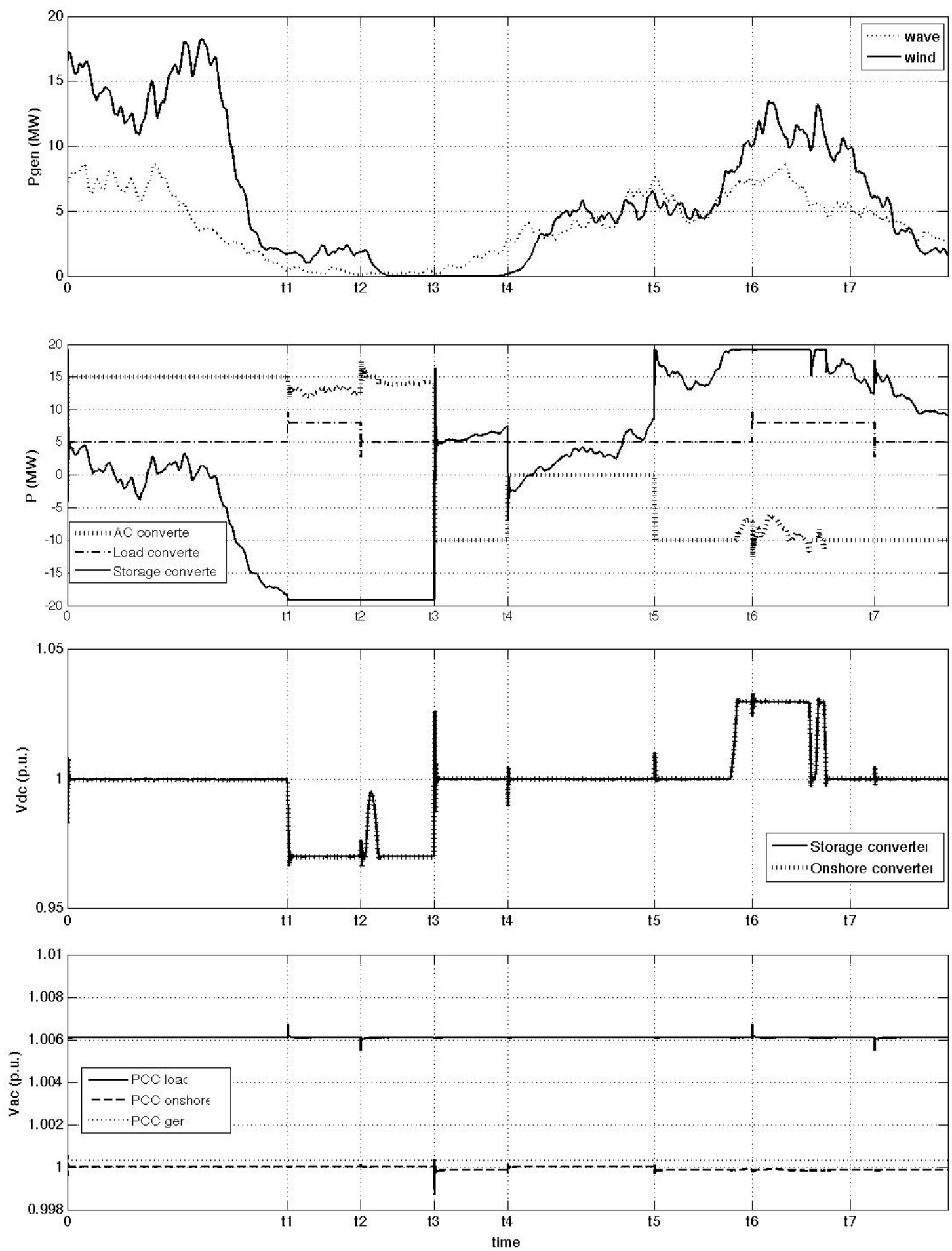

Fig. 7. Results for the events in Table II. (a) wind and wave generation (b) power sharing between: load, onshore grid and storage system (c) dc voltage level in the storage and the onshore converter (d) ac voltage level in the load, onshore grid and generation.

- $0<t<t_{1}$ : As there is a situation of high prices of the electricity in this period, the strategy is to export the amount of power scheduled by the onshore grid (15 MW).The storage system will act as slack bus following an $u_{d c}$ reference of 1 p.u. supporting the generation to supply the load and the $\mathrm{AC}$ requirements.

- $t_{1}<t<t_{2}$ : The increase of $3 \mathrm{MW}$ in the load forces the storage element to reach its limit of power transfer, so it is no longer able to control de dc voltage and works as a constant $\mathrm{P}$ terminal delivering $20 \mathrm{MW}$. Thus, the converter from the AC grid starts to act as voltage determining terminal controlling the dc voltage at its lower reference 0.97 p.u.

- $t_{2}<t<t_{3}$ : The demand returns to its initial value and the udc control is still under the onshore converter.

- $t_{3}<t<t_{4}$ : In $t_{3}$, it starts the hypothesis of low electricity prices. Thus, the strategy turns into keeping the storage at high levels of capacity, by means of the own generation of the platform or 
buying it (10 MW in this case) from the onshore network, for a later use at better prices. Moreover, the renewable generation is very low, and the ac grid needs to supply the load.

- $\mathrm{t}_{4}<t<\mathrm{t}_{5}$ : The connection with the onshore grid is lost att4, so the multiuse platform needs to operate in islanding mode. The generation is sufficient for the load demanded and the storage system is in charge of the dc voltage and acts as slack, keeping the power difference between generation and demand.

- $\quad t>t_{5}$ : The connection with the continental grid is reestablished. When the offshore generation reaches a certain level, the storage system is unable to admit more power transfer, so the dc voltage control will be charge of the ac converter again. But in this case, to its upper level of 1.03 p.u.

\section{Conclusions}

A multiterminal dc network is proposed for offshore multi-use platform integration into an onshore grid. A voltage margin method is used for developing control strategies. It is found that this methodology is capable of:

- Integrating storage systems in offshore platforms in order to handle different market conditions, operating scenarios and islanding operation.

- Holding stable steady state performance during different dispatch schemes.

- Overcoming transient performance during loss of DC terminals or AC onshore grid faults, although special treatment is needed for the definition of the voltage margin.

- $\quad$ Securing uninterruptible power supply to the load in all the study cases.

- The platform is capable of working in islanding mode when the continental DC link is lost.

The future research will be in the line of optimizing the quartet: offshore generation, load supply, storage and power transfer with the continental grids. This will lead to the realization of an economic analysis considering costs, inversion and benefits and the development of tools to integrate the electricity market conditions in the control system.

\section{Acknowledgement}

The authors would like to thank the Fundación para el Fomento en Asturias de la Investigación Científica Aplicada y la Tecnología (FICYT, Spain) within the frame Programa Severo Ochoa (Ref. BP11-153); and the Ministerio de Ciencia e Innovación and the European Union within the FEDER programme (research project reference IPT2011-1690-920000) for funding this work. The authors would also like to acknowledge the contribution from Nicolaos Cutululis from DTU Wind Energy for generating the wind speed data.

\section{References}

[1] http://ec.europa.eu/research/fp7/

[2] www.cei.uniovi.es/ energia

[3] L. Xu, B. W. Williams, and L. Yao, "Multiterminal DC transmission systems for connecting large offshore wind farms," in 2008 IEEE Power and Energy Society General Meeting Conversion and Delivery of Electrical Energy in the 21st Century, 2008, pp. 1-7.

[4] A. Ekstrom, "Multiterminal HVDC systems in urban areas of large cities," IEEE Transactions on Power Delivery, vol. 13, no. 4, pp. 1278-1284, 1998.

[5] J. G. Ciezki and R. W. Ashton, "Selection and stability issues associated with a navy shipboard DC zonal electric distribution system," IEEE Transactions on Power Delivery, vol. 15, no. 2, pp. 665-669, Apr. 2000.

[6] T. Haileselassie, M.Molinas and T.Undeland, "Multiterminal VSC-HVDC System for Integration of Offshore Wind Farms and Green Electrification of Platforms in the North Sea" Nordic Workshop on Power and Industrial Electronics, June 9-11, 2008. [7] C.D Baker and R. Whitehouse, "Autonomous Converter Control in a Multiterminal HVDC System" in 9th IET International Conference on AC and DC Power Transmission, pp. 1-5, 2010.

[8] R. T. Pinto, S. F. Rodrigues, P. Bauer, and J. Pierik, "Comparison of direct voltage control methods of multi-terminal DC (MTDC) networks through modular dynamic models" Power Electronics and Applications (EPE 2011), Proceedings of the 2011-14th European Conference on, pp. 1-10.

[9] L. Gengyin, Y. Ming, Z. Ming, and Z. Chenyong, "Modeling of VSC-HVDC and control strategies for supplying both active and passive systems," in 2006 IEEE Power Engineering Society General Meeting, 2006, p. 6 pp.

[10] Z. Keliang, F. Xiaofan, C. Ming, Z. Xiaodong, W. Wei, and W. Tong, "Topologies and control of VSC-HVDC systems for grid connection of large-scale off-shore wind farms," Electrical Machines and Systems, 2008. ICEMS 2008. International Conference on, pp. 2357-2361.

[11] O. Gomis-Bellmunt, J. Liang, J. B. Ekanayake, K. Rosemary, and N. Jenkins, "Topologies of multiterminal HVDC-VSC transmission for large offshore wind farms," Electric Power Systems Research, vol. 81, no. 2, pp. 271-281, 2011.

[12] R. Sabzehgar and M. Moallem, "A review of ocean wave energy conversion systems," in 2009 IEEE Electrical Power \& Energy Conference (EPEC), 2009, pp. 1-6.

[13] D. Valerio, P. Beirao, M. J. G. C. Mendes, and J. Sa da Costa, "Comparison of control strategies performance for a Wave Energy Converter," in 2008 16th Mediterranean Conference on Control and Automation, 2008, pp. 773-778.

[14] A. S. Bahaj, "Development of marine current turbines for electricity production," in 2011 IEEE Power and Energy Society General Meeting, 2011, pp. 1-4.

[15] Y. A. Wang, J. T. Boys, and A. P. Hu, "Modelling and Control of an Inverter for VSC-HVDC Transmission System with Passive Load," in 2008 Joint International Conference on Power System Technology and IEEE Power India Conference, 2008, pp. 1-6.

[16] M. M. Zakaria Moustafa and S. Filizadeh, "Simulation of a VSC transmission scheme supplying a passive load," in 2008 34th Annual Conference of IEEE Industrial Electronics, 2008, pp. 942-946.

[17] T. Nakajima and S. Irokawa, "A control system for HVDC transmission by voltage sourced converters," in 199 IEEE Power Engineering Society Summer Meeting.Conference Proceedings (Cat. No.99CH36364), vol. 2, pp. 1113-1119. 